\title{
Absence of effect of nasal continuous positive-airway pressure on the esophageal phase of nutritive swallowing in newborn lambs
}

Djamal Djeddi MD PhD, ${ }^{1,2}$ Danny Cantin, ${ }^{1}$ MSc student, Nathalie Samson PhD, ${ }^{1}$ Hao Tian, MD student, ${ }^{1}$ Jean-Paul Praud MD PhD ${ }^{1}$

${ }^{1}$ Neonatal Respiratory Research Unit, Departments of Pediatrics and Physiology, Université de Sherbrooke, QC, Canada, J1H 5N4; ${ }^{2}$ Department of Pediatrics, Université Picardie Jules Verne, Amiens, France

Short title: nasal continuous positive-airway pressure and nutritive swallowing

Word count of manuscript body: 2900 Number of figures: 0; Number of tables: 1

Address for correspondence and proofs:

Djamal Djeddi, MD PhD

Departments of Pediatrics and Physiology

Université de Sherbrooke

J1H 5N4, QC Canada

Tel: (819) 346-1110, ext 14872

Fax: (819) 564-5215

email: Djamal-Dine.Djeddi@Usherbrooke.ca

Conflicts of Interest and Source of Funding: The authors gratefully acknowledge the MMS Company (Enschede, Holland) for the gracious lending of the MII-pH monitoring equipment. Djamal Djeddi was supported by the Department of Pediatrics, Amiens University Hospital, France and the 2011 ChiesiJFRN scholarship. The study was also supported by the Canada Research Chair in Neonatal Respiratory Physiology allocated to Jean-Paul Praud and the Canadian Institutes of Health Research. Jean-Paul Praud is a member of the FRSQ-funded Clinical Research Center Étienne-Le Bel, Sherbrooke University Hospital, Quebec, Canada. 
Author contributions: Study design: Djamal Djeddi, Nathalie Samson, Jean-Paul Praud. Experiments: Djamal Djeddi, Danny Cantin, Hao Tian, Nathalie Samson. Data analyses: Djamal Djeddi, Jean-Paul Praud. Manuscript writing: Djamal Djeddi, Jean-Paul Praud, Nathalie Samson. 


\section{ABSTRACT}

It is currently recommended to start oral feeding in premature infants as soon as possible, often at an age where nasal continuous positive airway pressure (nCPAP) is still required for ventilatory support. Our previous data showed that application of nCPAP up to $10 \mathrm{cmH} 20$ in full-term lambs had no deleterious effect on cardiorespiratory safety, feeding efficiency or on nutritive swallowing-breathing coordination. Besides fear of swallowing-breathing coordination disturbances, esophageal motility disruption by nCPAP could be a reason to delay oral feeding. To our knowledge, no study has focused on the effects of nCPAP on esophageal motility in the neonatal period. The aim of the present study was therefore to further assess the effects of nCPAP on oral feeding by assessing its effects on the esophageal phase of nutritive swallowing (nutritive esophagodeglutition). Six full-term lambs, aged 2-3 days, underwent esophageal Multichannel Intraluminal Impedance-pH monitoring (MII-pH). Lambs were bottle-fed under two randomized conditions, namely spontaneous breathing and nCPAP $6 \mathrm{cmH}_{2} \mathrm{O}$. Beyond confirmation of unaltered feeding efficiency, analysis of multiple variables measured by impedance monitoring revealed that nCPAP-6 does not alter nutritive esophagodeglutition in any way (nCPAP vs. spontaneous breathing, $p>0.1$ for all variables). In conclusion, beyond offering further support to neonatologists pleading for initiation of oral feeding in infants still on nCPAP, the present results set the foundations for similar clinical studies in preterm human infants to confirm the absence of effects of nCPAP on nutritive swallowing.

Keywords: swallowing; animal model; neonates; multichannel impedance monitoring; ventilatory support; esophageal motility.

\section{INTRODUCTION}

Initiation of oral feeding represents a serious challenge in neonatal intensive care units (NICU). Delayed introduction of oral feeding is associated with delayed progression of oral feeding skills. This in turn prolongs hospital stay and increases the risk of feeding problems, which can persist into early childhood [1, 2]. The fact that preterm infants are often dependent on nasal continuous positive airway pressure (nCPAP) for several 
weeks [3] represents a further hurdle. Indeed, nCPAP is often considered a contraindication for initiation of oral feeding [4], in view of the inhibitory effect of CPAP on the swallowing reflex [5] and by fear of the cardiorespiratory consequences of laryngeal penetration and pulmonary aspiration of milk [6-8]. Several neonatologist teams nevertheless initiate oral feeding in preterm infants while on nCPAP, as soon as cardiorespiratory stability is present and the newborn is ready from a neurobehavioral standpoint [9-12]. This has been done however in the absence of formal data on the consequences of nCPAP on oral feeding. Recently, we have shown that application of nCPAP up to $10 \mathrm{cmH}_{2} \mathrm{O}$ in full-term lambs has no deleterious effect on feeding safety and efficiency or on the overall nutritive swallowing-breathing coordination [13].

Esophageal motility is an important component of swallowing. When esophagodeglutition is altered, the overall swallowing efficiency can be seriously disrupted. Abnormal esophageal motility has recently been documented in a number of neonatal situations, including premature birth $[14,15]$, gastroesophageal reflux disease [16] and esophageal atresia [17]. To our knowledge, the effects of nCPAP on esophagodeglutition during oral feeding are unknown. Therefore, the aim of the present study was to assess the effects of nCPAP on esophagodeglutition during bottle-feeding in newborn lambs, testing the hypothesis that nCPAP has no significant effect on the esophageal phase of nutritive swallowing.

\section{SUBJECTS AND METHODS}

Six full-term lambs aged between 2 to 3 days and weighing $3.9(0.4) \mathrm{kg}$ were included in a study on the effects of nCPAP on gastroesophageal reflux (ongoing study). In addition, the protocol design included the assessment of the effects of nCPAP on nutritive esophagodeglutition, which is the focus of the present study. All lambs were cared for without their mother upon arrival in our animal quarters due to the need to get used to bottlefeeding. Lambs could move freely in a Plexiglas chamber $\left(1.2 \mathrm{~m}^{3}\right.$, in agreement with recommendations by the Canadian Council for Animal Care for sheep housing) and were bottle-fed with reconstituted ewe milk ad libitum. The study was approved by the ethics committee for animal care and experimentation of the Université de Sherbrooke. 


\section{Experimental Equipment}

\section{$\underline{\text { Ventilatory equipment }}$}

Nasal continuous positive airway pressure was induced using the Infant Flow nCPAP system (Cardinal Health, Dublin, $\mathrm{OH}$ ) with heated, humidified air. A custom-built nasal mask [18] was installed on the muzzle of each lamb to deliver nCPAP, in such a manner that the lamb was able to open its mouth and drink from a bottle [13].

\section{$\underline{\text { Recording equipment }}$}

The MII-pH catheter (diameter = $2 \mathrm{~mm}$, Unisensor, Portsmouth, USA) was inserted trans-nasally and its position confirmed by X-ray, as previously described [19]. External lamb instrumentation included i) subcutaneous needle-electrodes for recording electroencephalogram, electrooculogram (for the study on gastroesophageal reflux); ii) an electrocardiogram for continuous monitoring of heart rate (HR, bpm); iii) a pulse oximeter probe (Masimo Radical, Irvine, CA) attached at the base of the tail for continuous monitoring of oxygen hemoglobin saturation $\left(\mathrm{SpO}_{2}, \%\right)$; iiii) thoracic and abdominal bands of respiratory inductive plethysmography for continuous monitoring of respiratory rate $\left(R R, . \mathrm{min}^{-1}\right)$. The physiological signals were wirelessly transmitted and continuously recorded on a PC using AcqKnowledge (version 4.1; Biopac Systems, Montreal, Canada) and MMS (v8.2, MMS, Enschede, Holland) software. The entire recording period was also filmed using a webcam.

\section{Design of the study}

The study was performed without sedation. The MII-pH probe was left in place for $48 \mathrm{~h}$ to allow for comparison of two different conditions, namely no nCPAP (control) and nCPAP at $6 \mathrm{cmH}_{2} \mathrm{O}$ (nCPAP 6) in randomized order, performed at the same time of day on both days. The level of nCPAP was chosen on the basis of what is usually reported in clinical practice [20,21]. Standardized bottle-feeding was performed in each condition, 4 hours after beginning of the recording. The lambs were comfortably placed in a sling with loose restraints and offered a bottle filled with $75 \mathrm{ml}$ of reconstituted ewe's milk at ambient temperature $\left(26^{\circ} \mathrm{C}\right)$. The same bottle and teat were used for all lambs.

\section{$\underline{\text { Data analysis }}$}




\section{Nutritive esophagodeglutition}

Definitions of swallowing variables using MII-pH have been described previously [22]. Bolus entry at a specific level was measured at the $50 \%$ point between pre-swallow impedance baseline and lowest impedance point during bolus presence. Bolus exit was determined as the return to this $50 \%$ point on the impedance recovery curve. Nutritive esophagodeglutition was evaluated by manual assessment of the following specific motility parameters:

- Bolus presence time (BPT): time elapsed between bolus entry and bolus exit at each impedancemeasuring site.

- $\quad$ Total bolus transit time (TBTT): time elapsed between bolus entry at the most proximal recording segment and bolus exit at the most distal recording segment.

- Segmental transit time (STT): time elapsed between bolus entry at a given level above lower esophageal sphincter (LES) and bolus exit at the next lower level.

- Total propagation velocity: speed with which the bolus crosses all of the impedance channels.

\section{Cardiorespiratory variables}

Baseline HR, RR and SpO2 values were averaged over 1 min just before feeding. Recovery times after feeding were assessed, for the purpose of the present study, by calculating the percent change in $H R$ and RR after feeding $\left[\left(H R_{B L}-H R_{5 m n}\right) * 100 / H R_{B L}\right]$ and $\left[\%\right.$ ch $\left.R R=\left(R R_{B L}-R R_{5 m n}\right) * 100 / R R_{B L}\right]$, with $H R_{B L}$ and $R R_{B L}$ representing the baseline $H R$ and $R R$ values averaged over 1 min before feeding, and $H R_{5 m n}$ and $R R_{5 m n}$ representing the mean $\mathrm{HR}$ and mean RR values observed 5 minutes after feeding. Variations in $\mathrm{SpO}_{2}$ could not be reliably measured during or just after feeding, due to too many signal artifacts in several lambs (large body movements for respiratory inductive plethysmography bands and frequent tail wagging for $\mathrm{SpO}_{2}$ ).

\section{Statistical analysis}

Statistical analyses were performed on raw data for all variables to compare nCPAP to no CPAP condition. Values are expressed as mean (standard deviation). Given the non normal distribution for all studied variables, 
the Wilcoxon signed rank test was used for all comparisons (SPSS version 20, Chicago, IL, USA).

\section{RESULTS}

Mean lamb body temperature was $39.6(0.4){ }^{\circ} \mathrm{C}$. Baseline $\mathrm{SpO}_{2}$ in control and nCPAP 6 conditions were respectively 95\% (2) and 96\% (1) before feeding. Mean HR (bpm) in control and nCPAP 6 conditions were respectively $179(7)$ and $202(12)$ before feeding and $204(17)$ and $213(11) 5$ minutes after feeding $(P>0.1$ for $\%$ change in HR). In addition, mean HR in control and nCPAP 6 conditions were respectively 188 (17) and 193 (18) during feeding $(P>0.1)$. Mean RR (bpm) in control and nCPAP 6 conditions were respectively $58(22)$ and 50 (14) before feeding and 56 (14) and 50 (14) 5 minutes after feeding ( $P>0.1$ for \% change in RR).

Suckling time during bottle-feeding was less than 2 minutes for all lambs. All esophagodeglutition variables were successfully studied in both conditions (Table 1). Nasal CPAP had no effects on the number of swallows [No CPAP: 39 (5); nCPAP 6: 38 (6), P > 0.1] and mean bolus volume [No CPAP: 0.5 (0.1) ml; nCPAP 6: 0.5 (0.1) $\mathrm{ml}, P>0.1]$. An absence of nCPAP effect was also observed for BPT for all studied segments, mean TBTT, total propagation velocity, mean STT as well as STT for all segments ( $P>0.1$ for all variables).

\section{DISCUSSION}

\section{Statement of principal findings}

The present study reveals that nutritive esophagodeglutition, as explored by $\mathrm{MII}-\mathrm{pH}$, is not altered by $6 \mathrm{cmH}_{2} \mathrm{O}$ nCPAP in full-term lambs. These unique findings can be considered as another step in the understanding of the physiology of oral feeding in newborns while on nCPAP.

\section{Nutritive esophagodeglutition}

Inferring the potential consequences of nCPAP on esophageal function from previous knowledge is not straightforward. Clinical observations of gastric distension during nCPAP application in neonates clearly show that air delivered at positive pressure into the upper airways can pass through the esophagus down to the stomach [23]. Alterations of esophageal function could then result from various reflexes elicited by distension 
of the upper airways, as well as of the esophagus and stomach. With regards to the upper airways, previous observations in adult humans showed that laryngeal stimulation by a 2 second-air pulse $(6 \mathrm{mmHg})$ induces upper esophageal sphincter (UES) contraction (laryngo-UES contractile reflex) [24]. However, while the latter may limit the passage of air into the esophagus, as well as alter esophagodeglutition, there is no evidence that this reflex is present when the distending pressure is applied for a period longer than a few seconds, as with the clinical use of nCPAP. In addition, slow esophageal distension has been shown to reflexly activate contraction of the UES and secondary peristalsis [25]. However, the net effect of such alterations on primary peristalsis is unknown, and, if they exist, they appear not to be significant, as least as judged in the present study by MII-pH.

There is limited data on the effect of nCPAP on gastroesophageal motility, especially in the neonatal period. The next important step is to document the impact of nCPAP on the lower esophageal sphincter, as well as on the potential triggering of gastroesophageal reflux in neonates. However, it is well accepted that nCPAP reduces gastroesophageal reflux in adult patients $[26,27]$, probably by limiting the nadir pressure and duration of lower esophageal sphincter relaxations [27].

\section{Limitations of the study}

The present results complete our previous observations that clinically relevant levels of nCPAP do not have deleterious consequences on the safety and efficacy of bottle-feeding, as well as on overall swallowingbreathing coordination in lambs [13]. However, transposition of the present results from newborn lambs to human infants must be made with caution. Indeed, anatomical differences with regards to the extent of striated muscle along the esophagus (upper third only in humans vs. entire esophagus in the sheep) [28], as well as bolus propagation velocity ( 5 to 10 times slower in humans vs. sheep) [19], are noticeable. On the other hand, there are clear similarities between the two species, including the presence of well-determined upper and lower esophageal sphincters recorded by manometry in the lamb (personal unpublished results), the fact that the preruminant lamb is monogastric in the first week of life [29] and the presence of spontaneous gastroesophageal refluxes, with several characteristics close to the human infant [19]. While no manometric 
exploration was performed during bottle-feeding attempts in the present study, it would be quite relevant to explore the esophageal pressure regimen by manometry during nCPAP, especially looking at the low esophageal sphincter resting pressure and relaxation.

A further limitation of the present study is related to the small number of lambs involved, which bears a risk of a type II error. The latter is minimized by showing that no significant difference is present for any variable, even with a probability level of 0.1 . Finally, the present results pave the way for further studies in human newborns with an adequate sample size to definitely confirm the hypothesis that nutritive esophagodeglutition is not altered by nCPAP application. Specific attention should be given to preterm newborns, in whom immaturity in itself, as well as previous complications of prematurity (e.g., respiratory or neurological), could be responsible for differing results.

\section{REFERENCES}

1. Barlow SM. Oral and respiratory control for preterm feeding. Curr Opin Otolaryngol Head Neck Surg. 2009;17:179-86.

2. Jones LR. Oral feeding readiness in the neonatal intensive care unit. Neonatal Netw 2012;31:148-55.

3. Mahmoud RA, Roehr CC, Schmalisch G. Current methods of non-invasive ventilatory support for neonates. Paediatr Respir Rev 2011;12:196-205.

4. Nyqvist KH. Early attainment of breastfeeding competence in very preterm infants. Acta Paediatr 2008;97: $776-81$.

5. Nishino T, Sugimori K, Kohchi A, et al. Nasal constant positive airway pressure inhibits the swallowing reflex. Am Rev Respir Dis 1989;140:1290-3.

6. Praud JP. Upper airway reflexes in response to gastric reflux. Paediatr Respir Rev 2010;11:208-12. 
7. St-Hilaire M, Samson N, Nsegbe E, et al. Postnatal maturation of laryngeal chemoreflexes in the preterm lamb. J Appl Physiol 2007;102:1429-38.

8. Thach BT. Some aspects of clinical relevance in the maturation of respiratory reflexes in infants. J Appl Physiol 2008;104:1828-34.

9. Bonner KM, Mainous RO. The nursing care of the infant receiving bubble CPAP therapy. Adv Neonat Care 2008;8:78-95.

10. de Klerk R. Nasal Prong Continuous Positive Airway Pressure: A Practical Guide. New York: Children's Hospital of New York, 2004.

11. Pfister RE, Launoy V, Vassant $C$, et al. Transition de l'alimentation passive à l'alimentation active chez le bébé prématuré. Enfance 2008;60:317-35.

12. Maastrup R, Bojesen SN, Kronborg $\mathrm{H}$, et al. Breastfeeding support in neonatal intensive care: a national survey. J Hum Lact 2012;28:370-9.

13. Bernier A, Catelin C, Ahmed MA, et al. Effects of nasal continuous positive-airway pressure on nutritive swallowing in lambs. J Appl Physiol 2012;112:1984-91.

14. Staiano A, Boccia G, Salvia G, et al. Development of esophageal peristalsis in preterm and term neonates. Gastroenterology 2007;132:1718-25.

15. Gupta A, Gulati P, Kim W, et al. Effect of postnatal maturation on the mechanisms of esophageal propulsion in preterm human neonates: primary and secondary peristalsis. Am J Gastroenterol 2009;104:411-9.

16. Di Pace MR, Caruso AM, Catalano $P$, et al. Evaluation of esophageal motility using multichannel intraluminal impedance in healthy children and children with gastroesophageal reflux. J Pediatr Gastroenterol Nutr 2011;52:26-30 
17. Di Pace MR, Caruso AM, Catalano $P$, et al. Evaluation of esophageal motility and reflux in children treated for esophageal atresia with the use of combined multichannel intraluminal impedance and $\mathrm{pH}$ monitoring. $J$ Pediatr Surg 2011;46:443-51.

18. Samson N, St-Hilaire M, Nsegbe E, et al. Effect of nasal continuous or intermittent positive airway pressure on nonnutritive swallowing in the newborn lamb. J Appl Physiol 2005;99:1636-42.

19. Djeddi D, Samson N, Praud JP. Milk temperature influences esophageal motility in the newborn lamb. J Pediatr Gastroenterol Nutr 2012 14. [Epub ahead of print] PubMed PMID: 22710998.

20. Morley CJ, Davis PG. Continuous positive airway pressure: scientific and clinical rationale. Curr Opin Pediatr 2008;20:119-24.

21. Roehr CC, Schmalisch G, Khakban A, et al. Use of continuous positive airway pressure (CPAP) in neonatal units - a survey of current preferences and practice in Germany. Eur J Med Res 2007;12:139-44.

22. Di Pace MR, Caruso AM, Farina F, et al Evaluation of esophageal motility and reflux in children treated for congenital diaphragmatic hernia with the use of combined multichannel intraluminal impedance and $\mathrm{pH}$ monitoring. J Pediatr Surg 2011;46:1881-6.

23. Mahmoud RA, Schmalisch G. Modern mechanical ventilation strategies in newborns: a review. Technol Health Care 2011;19:307-18.

24. Kawamura O, Easterling C, Rittmann $\mathrm{T}$, et al. Optimal stimulus intensity and reliability of air stimulation technique for elicitation of laryngo-upper esophageal sphincter contractile reflex. Ann Otol Rhinol Laryngol 2005;114:223-8.

25. Lang IM, Medda BK, Shaker R. Mechanisms of reflexes induced by esophageal distension. Am J Physiol Gastrointest Liver Physiol 2001;281:G1246-63. 
26. Kerr P, Shoenut JP, Millar T, et al. Nasal CPAP reduces gastroesophageal reflux in obstructive sleep apnea syndrome. Chest 1992; 101:1539-44.

27. Shepherd KL, James AL, Musk AW, et al. Gastrooesophageal reflux symptoms are related to the presence and severity of obstructive sleep apnoea. J Sleep Res 2011;20:241-9.

28. Cavuşoğlu H, Tuncer C, Tanik C, et al. The impact of automatic retractors on the esophagus during anterior cervical surgery: an experimental in vivo study in a sheep model. J Neuro Surg Spine 2009;11:547-54.

29. Pfannkuche H, Schellhorn C, Schemann M, et al. Age-associated plasticity in the intrinsic innervation of the ovine rumen. J Anat 2003;203:277-82. 